\title{
Knowledge, Attitude and Practice among the Moi University College of Health Sciences Finalists Undergraduate Students at Moi Teaching and Referral Hospital on Environmental Carcinogens in Eldoret, Uasin Gishu County, Kenya
}

\author{
Zainabu Kadesa Ayumba ${ }^{1 *}$, Taratisio Ndwiga ${ }^{2}$, Barry Ramadhani Ayumba ${ }^{3}$ \\ ${ }^{1}$ School of Public Health, Texila American University, Guyana \\ ${ }^{2}$ School of Public Health, Masinde Muliro University, Kakamega, Kenya \\ ${ }^{3}$ School of Medicine, Moi University, Eldoret, Kenya
}

\begin{abstract}
This study aimed to bridge the gap between cancer and environmental causes, push for improved prevention, early screening, and better surveillance on indicators of poor health linked to cancer. The objective assessed knowledge, attitude, and practice among Moi University College of Health Sciences finalist undergraduate students on environmental carcinogens in Eldoret, Kenya. The study site was MTRH, with a cross-sectional study design. The study population was the adult finalist undergraduate students in the College of Health Sciences at MTRH. Inclusion criteria: adult finalist undergraduate students in the College of Health Sciences willing to share information and consenting to participate. Sample Size was determined after the census of all the participants and meeting inclusion criteria. Mixed sampling was used. Data collection tools were a pre-validated structured questionnaire, observation checklist, and secondary data. Data collection was done using Google forms. Data were cleaned and checked for completeness. Statistical analysis and cross-tabulation for variables were done using SPSS version 26. Data Presentation was through tables, graphs, and prose formats. The results of the study were as follows: There were 40 males and 22 females, ratio-1.82:1. Modal age was 22years (19.67\%). Prior to joining the university, $61.29 \%$ had encountered cancer cases. $36 \%$ agreed that they were not aware of predisposing factors, while $32 \%$ and $12 \%$ agreed that tobacco users and factory workers were predisposed, respectively. 28 respondents used plastic containers, $1.61 \%$ used tobacco, and 21 took alcohol. 92\% were never screened for cancer, though 17 females and 26 males did self-examination at least once a month.
\end{abstract}

Keywords: Environmental carcinogens, Knowledge, Attitude and Practices.

\section{Introduction}

A carcinogen is defined as any substance that could cause cancer. It is also defined as an agent that has the capacity to cause cancer in humans [1]. This could mean elements, compounds, solutions, mixtures, or pathogens that could, on exposure to someone in the environment, encourage the development of cancer. Carcinogens are normally classified into three significant categories: chemical (which includes the ones that come from biological sources), physical and oncogenic (including cancer-causing viruses) carcinogens [2, 3]. They are present in the environment because of lifestyle factors (nutrition, tobacco use, physical activity), naturally occurring exposures (UV light, radon gas, infectious agents), medical treatments (radiation and medicine), workplace and household exposures, and, lastly pollution.

In recent years, the Kenyan media have published and aired news pieces that have constantly highlighted just how vulnerable the country is in managing and controlling cancer 
cases, right from the bottom of the pyramid at the community to the country's biggest hospitals. Various news segments from Kenya Television Network (KTN), National Television (NTV), and Citizen Television have sent reporters to places where pollution of water, soil, and the air have affected the lives of the local residents negatively.

In 2019, NTV did a two-month river pollution investigative project titled "Toxic Flow" that followed River Nairobi from its source in Kiambu to the mouth of River Sabaki in Kilifi County. The project led the National Environment Management Agency (NEMA) to shut down four companies that were discharging waste-water into River Nairobi. Some of them did not have efficient wastewater treatment plants, while others needed to improve the quality of the emissions they discharged into the air [4]. Kenya today is still faced with poor guidelines on tobacco use and smoking. Lead poisoning, poor surveillance of the remote and marginalized communities (Marsabit) communities, and pollution were the key reasons of rapid cancer cases in recent years. Residents from Marsabit and their livestock were repeatedly exposed to bentonite, zinc, nitrates, and nitrites from oil prospection activities. The water also had high levels of arsenic $[5,6,7]$.

Bentonite contaminated with crystalline silica, lead, arsenic, mercury or other carcinogens can cause silicosis and lung cancer upon ingestion. Upon prolonged exposure, bentonite can cause silicosis and lung cancer due to the naturally occurring quartz $[8,9]$. Nitrites and nitrates form nitrosamines which increase the risk of developing cancer [9]. They also form N-nitroso compounds (NOC) when they react with amines and amides. Nitrates present in drinking water raise incidences of colorectal, ovarian, thyroid, kidney, and bladder cancers. Nitrites, though not closely monitored, were associated with high mortality rates in China for people with esophageal cancer,
Europe, and South America (stomach cancer) [10].

Zinc in excess increases the risk of prostate cancer incidences, with cases of immune dysfunction and higher levels of circulating insulin-like growth factor I that predisposed them to prostate cancer development [11]. Excess zinc is known to impair copper utility in the body. There is, however, no sufficient evidence showing that zinc is teratogenic or genotoxic, but enough indicating that it is cytotoxic (kill cells) [8].

Arsenic in its inorganic form, and its compounds, are known to cause skin, bladder, and lung cancers when they come in contact with human beings. People get exposed to it through drinking, preparing food, and irrigating food crops using contaminated water, industrial processes, eating contaminated food, and smoking tobacco [9].

The Kenyan health system is burdened to the point where cancer and other NCDs, misdiagnosis, and late diagnosis are quite common. It has become a burden (socioeconomic, psychological, etc.) to the individual, the family, the community, and even the nation. Community health volunteers have limited experience in handling cancer sensitization and education. The same could be said about health education and promotion efforts centered on schools and even hospitals. Most microeducation and health talk sessions delivered in institutions centre around handwashing, malaria prevention, and safe sex, yet cancer is hugely ignored.

While many claim that cancer could be treated and patients could not have a relapse, it is entirely possible for them to encounter it if their environment and lifestyles still allow them to come in contact with the causative and triggering agents. It was not until quite recently that the tracing and tracking of genes and conditions that were responsible for the development of cancer were started. As Kenya is a middle-income country, not many people 
could benefit from these forms of technological developments and would instead have to rely on poor, accidental, or late diagnoses to learn about the possible causes of cancer in the hospital when seeing a specialist.

This health crisis requires a multiple solution approaches. First of all, the Ministry of Health and its health policy implementing partners need to change their implementing strategy by boosting knowledge on environmental carcinogens. This can be done by directing the focus towards a community-friendly approach that can create a high suspicion index for cancer. This will enable suspected cases to come out early for appropriate care in health institutions.

Secondly, allowing health programs to focus on the need to build a positive outlook on cancer screening and cancer positive tests will help the community to have a more positive attitude. It will also minimize negative attitudes towards environmental carcinogens. A positive attitude is crucial in making the community members have a better approach towards handling cancer issues. This case is especially important in situations where the community members cannot avoid exposure to environmental carcinogens.

The third method can have the Ministry of Health partner with the Ministries of Government, Industry, Development, Education, and other important stakeholders to reduce exposure to environmental carcinogens. It should also partner with NGOs and FBOs to help the community members know more about their health and surroundings and participate in community-based initiatives like tree planting to increase tree coverage and use cleaner fuels to reduce poisonous compounds in the air. It should also aim to train the community health volunteers and the members themselves on the need to observe and do more good practices reducing environmental carcinogens. That is the best way to make early diagnosis of cancer, which will enable appropriate action to be taken to have better health outcomes.
The fourth method will focus on ensuring that the health education and promotion programs are properly funded for the long run in order to educate the community. This will be done on the need to observe and ensure that preventive and control measures against carcinogens are encouraged in the community. This is the best and cheapest way to safeguard the health of individuals in the community.

Lastly, further research is needed on uncovering what the true picture is on the community. This is because the researcher noted that a lot of research work has been done on knowledge and attitude but hardly came across the literature which touched extensively on practices on environmental carcinogens. Further research with particular interest on this aspect is highly recommended.

The study's limitations were as follows; the respondents would probably not fill the Google doc forms (questionnaires) honestly and would probably interpret some of the questions wrongly. Respondents might have chosen to opt-out due to possible expectations on remuneration to complete the questionnaires. The participants who responded were initially very few because they were preparing for exams. The challenge posed by the virtual platform was beyond the control of respondents and even the researcher. Finally, during analysis, the various multiple answers the respondents picked complicated the process.

The achievements of the study were tied to the challenges. First, the researcher convinced them to be honest and was always readily available to interpret any issues or give help. The researcher was able to give proper prior information on no monetary gains by participation before the participants took part in the study. To cope with low participant numbers, the researcher kept on pleading and reminding them through their class representatives to respond. As for administering the questionnaires, the link was always available for access until $28^{\text {th }}$ December 2020 . This date was exactly two weeks after the 
intended date of closing the participation. The researcher also recorded and combined numerous replies to create new variables that could answer the questions posed by the study.

\section{Materials and Methods}

\section{Study Site}

The College of Health Sciences situated at Moi Teaching and Referral Hospital was the study area of this research. The hospital is located in Elgon View Estate, Town Ward, Eldoret Municipality, Uasin Gishu County, and former Rift Valley Province, Kenya. The local catchment population is estimated to be 475,716 in number. However, it generally serves a catchment area of about 20 million people who reside in Kenya, Eastern Uganda, South Sudan, and Tanzania [12].

Eldoret was selected as a study site due to its proximity to the investigator, the diverse population settled in the urban area, the fact that it plays host to the second public national referral hospital in Kenya and serves a huge population of people. The hospital is also a training ground for both graduate and undergraduate students of the diverse population from various health, health allied, and medical courses.

\section{Study Design and Sampling}

A descriptive cross-sectional study design was used because it is relatively cheap and quick to carry out. It also enables the collection of extensive information from a representative sample, which can be used to analyze the whole population in the study area [13]. The study population was the finalists' undergraduate adult student community of the CHS of Moi University who regularly utilized Moi Teaching and Referral Hospital for their education and practice.

The respondents included in the study were all aged 18 years and above, able to understand express themselves in English and Kiswahili, were in their final year of study, and compliant in the use of online platform. Those excluded were under the age of 18 and not willing to participate. Final year adult students not available, and those who participated in questionnaire pretesting were excluded.

A census of the adult final year students participating was done using the class-lists. This already created the strata (Dentistry-year 5; Environmental Health-year 4; Medical Laboratory Sciences-year 4; Medical Psychology- year 4; Medicine-year 6; Nursingyear 4; and Physical Therapy-year 4). Sample size determination depended on the already established eligibility criteria and the number of students in their final year of study in the College of Health Sciences schools, located at MTRH, Eldoret, Kenya. The average number of final year students per program was outlined: Dentistry-16; Environmental Health-30; Medical Laboratory Sciences-15; Medical Psychology-22; Medicine-85; Nursing-53; and Physical Therapy-22. This gave a total of 243 final year students in the College of Health Sciences of Moi University. Taking into consideration the inclusion criteria, the final number decreased below 243, and the number of those who responded was taken as the final sample size. The COVID-19 pandemic had a great negative impact to this study.

\section{Piloting and the Final Study}

The pretest of the interview schedule was virtually done on the first week of November 2020 at a population with similar characteristics, preferably the then-current finalist class who were about to do the end of year examination (2020) and were then to graduate from the CHS. A proportion of about $10 \%$ from each program (total=23) was involved. This helped improve the questionnaire and hence validity.

After two weeks (third week of November 2020), the questionnaires (Google doc forms) were uploaded and sent virtually (on-line) to the student program representative to distribute to class members. The filled-up questionnaires were then downloaded, received, and checked 
for completeness using a checklist (second week of December 2020). Data were then coded, and the combinations were done and acronymed. Secondary data was checked in The Eldoret Cancer Registry (Moi University/AMPATH/MTRH) Office.

\section{Statistical Methods}

Descriptive statistics were done using various techniques involving a measure of central tendency, cross-tabulation and performing statistical analysis, and summarizing the data into tables and graphs. SPSS version 26 was used for the analysis of research variables. Statistical inferences on associations between study variables were derived from the Chi-square and $p$-value set at less than 0.05 as statistically significant. This process took place in the first week of January 2021. Data was presented using diagrams (tables, charts, and graphs) and prose format. This was in the second week of January 2021. Microsoft PowerPoint was used in an oral presentation, while Microsoft Word was used in writing up the report.

The principal investigator sought approval from the Department of Environmental Health in Texila American University, Institutional Research and Ethics Committee (IREC), and the management teams of Moi Teaching and Referral Hospital and Moi University College of Health Sciences. Consent was sought from the final-year adult students participating in the study. The privacy, confidentiality, dignity, and beneficence of the participants formed the pillars of the study.

\section{Results}

To determine the association, the researcher chose to cross-tabulate certain variables with others. These variables were picked because they resonated best with the study. Out of 51 variables, the researcher picked four constant ones that were used to cross-tabulate with one new variable and three constant variables. For Knowledge, the second variable was 'Knowledge on Cancer before joining Moi University' while for Attitude, it was 'Cancer is a punishment from God.' For practice, the new variable was 'Duration of keeping windows open at home.' Finally, for Prevention and Control, the variable was 'Screened for Cancer before.'

\section{Knowledge}

On cross-tabulation 'Encountered Cancer before' (knowledge) and 'Knowledge on Cancer before joining Moi University (knowledge), it yielded $\chi^{2}=51.688, \mathrm{df}=50$, and $p$-value of 0.408 . 'Monthly selfexamination' yielded $\chi^{2}=7.831, \mathrm{df}=10$ and $p$ value of 0 . 645. These values have been illustrated on Table 6 in the Appendix.

The gender of the respondents is illustrated in Table 1. Over half $(61.29 \%)$ of the respondents admitted to encountering cancer before coming to the university, as illustrated in Figure. 1. All of the respondents selected a factor that predisposed people to cancer. These options were genetic inheritance, the environment, pathogens, and the opportunity to write in other factors.

Table 1. Gender of Participants

\begin{tabular}{|l|l|}
\hline Gender & Percentage \\
\hline Male & 64.52 \\
\hline Female & 35.48 \\
\hline Total & 100.00 \\
\hline
\end{tabular}




\section{Attitude}

On cross tabulation, 'Cancer is limited to certain people groups' (attitude) and 'Cancer is a punishment from God' (attitude) yielded $\chi^{2}=$ 3.479 , df $=4$ and $p$-value $=0.481$. 'Monthly self-examination for Cancer' yielded $\chi^{2}=$ 12.350, $\mathrm{df}=10$, and $p$-value $=0.262$. These values have been illustrated in Table 7 , in the Appendix.

The majority (85.48\%) of the respondents said that cancer was not limited to certain people groups, as seen in Figure 2. Approximately $90 \%$ of the respondents said that cancer was not a punishment from God. These results have been illustrated in Figure 3.

\section{Practices}

On cross tabulating 'Smoke cigarettes' (practices) and 'Monthly self-examination for Cancer' (prevention and control) they yielded $\chi^{2}=11.760, \mathrm{df}=15, p$-value $=0.697$. These values have been illustrated in Table 8 , in the Appendix. The majority of them $(88.7 \%)$ did not smoke cigarettes, as shown in Table 2 . Fifty two out of sixty-two $(85.25 \%)$ respondents said they did not open their windows daily. This information has been plotted against the type of house in Table 3.

Table 2. Responses to Smoking Cigarettes

\begin{tabular}{|l|l|}
\hline Response & Percentage \\
\hline Yes & $1.61 \%$ \\
\hline Yes, I tried to quit before & $4.84 \%$ \\
\hline No & $88.71 \%$ \\
\hline No, I quit & $4.84 \%$ \\
\hline
\end{tabular}

Table 3. Duration of Opening Windows at Home

\begin{tabular}{|l|l|l|l|l|}
\hline \multicolumn{2}{|c|}{} & \multicolumn{3}{l|}{ Type of house } \\
\cline { 3 - 5 } \multicolumn{2}{|c|}{} & Temporary & Semi-permanent & Permanent \\
\hline \multirow{3}{*}{$\begin{array}{l}\text { Duration of opening } \\
\text { windows at home }\end{array}$} & Don't have windows & 1 & 0 & 3 \\
\cline { 2 - 5 } & 1 hour & 0 & 0 & 7 \\
\cline { 2 - 5 } & 2 hours & 0 & 0 & 4 \\
\cline { 2 - 5 } & 3 hours & 0 & 17 & 36 \\
\cline { 2 - 5 } & Entire day & 0 & 0 & 0 \\
\cline { 2 - 5 } & Total & 1 & 17 & 50 \\
\hline
\end{tabular}

\section{Prevention}

On cross-tabulating 'Monthly selfexamination for Cancer' (prevention and control) and all the other four sample variables, they all yielded $p$-values above 0.05 . These values were illustrated in Table 9 , in the Appendix.
Over $90 \%$ of the respondents had not been screened for cancer, as indicated in Table 4. Finally, there were 17 female students against 26 male students who conducted selfexaminations for cancer at least once every month. This has been indicated in Table 5 . 
Table 4. Screened for Cancer Before

\begin{tabular}{|l|l|l|l|}
\hline Yes, Screened for which cancer type & Screened for Cancer before & Yes & No \\
\cline { 2 - 4 } & Ovarian cancer & 0 & 0 \\
\cline { 2 - 4 } & Lung cancer & 0 & 0 \\
\hline & Breast cancer & 1 & 0 \\
\hline & Thyroid cancer & 1 & 0 \\
\cline { 2 - 4 } & Others & 0 & 0 \\
\cline { 2 - 4 } & I don't know & 0 & 0 \\
\hline Total & 2 & 60 \\
\hline
\end{tabular}

Table 5. Self-examination on a Monthly Basis

\begin{tabular}{|l|l|l|l|}
\hline Monthly self-examination & & Sex \\
\cline { 2 - 4 } & & Female & Male \\
\cline { 2 - 4 } & Once & 6 & 11 \\
\cline { 2 - 4 } & Twice & 1 & 1 \\
\cline { 2 - 4 } & Thrice & 3 & 3 \\
\cline { 2 - 4 } & Once a week & 6 & 2 \\
\cline { 2 - 4 } & Every day & 1 & 9 \\
\cline { 2 - 4 } & Never & 5 & 13 \\
\hline
\end{tabular}

Table 6. Encountered Cancer before Versus Cancer Knowledge before Joining MOI University, Cancer is Limited to People Groups, Smoke Cigarettes, and Monthly Self-examination for Cancer

\begin{tabular}{|l|l|l|l|}
\hline Encountered Cancer Before & $\chi^{2}$ & df & $\boldsymbol{p}$-value \\
\hline $\begin{array}{l}\text { Knowledge on Cancer before Moi University (Knowledge versus } \\
\text { Knowledge) }\end{array}$ & 51.688 & 50 & 0.408 \\
\hline Cancer is limited to people groups (Knowledge versus Attitude) & 32.416 & 4 & 0.000 \\
\hline Smoke cigarettes (Knowledge versus Practice) & 25.304 & 6 & 0.000 \\
\hline Monthly self-examination (Knowledge versus Prevention and Control) & 7.831 & 10 & 0.645 \\
\hline
\end{tabular}

\section{Discussion}

The odds of practicing prevention increased by $15 \%$ for every increase in knowledge score however, the association was not significant $(p=0.577)$. For every one score increase in good practice, the odds of practicing prevention increased by $54 \%$. The probability of practicing prevention would then be reduced by $29 \%$ for every increase in good attitude score. The only practice was statistically associated with prevention $(\mathrm{p}=0.042)$. This has been illustrated in Table 10 and Table 11 in the Appendix.

\section{Knowledge}

There was no significant association noted between 'Encountered Cancer before' (knowledge) and 'Knowledge on Cancer before joining Moi University (knowledge) as it yielded $\chi^{2}=51.688, \mathrm{df}=50$, and $\boldsymbol{p}$-value of 0.408 . As seen in 'Monthly self-examination', there is no significant association with practice, which yielded $\chi^{2}=7.831, \mathrm{df}=10$, and a $p$-value of 0.645. However, there is a significant association with 'Cancer is limited to certain 
people groups' (attitude) and 'Respondent's smoke cigarettes' (practice). This means that Attitude and Practices are associated closely with knowledge, and they might affect each other.

More than half of the respondents (61.29\%) admitted to encountering cancer before coming to the university. This could be attributed to the possibilities that these students (with knowledge) had prior exposure to the disease either through someone close to them, like a friend, family member, or teacher, or personally. The other reason could be due to volunteer work in the community for some of the students prior to joining the college. However, the Researcher found no statistical significance $(\boldsymbol{p}=0.408)$ between students' personal knowledge before joining Moi University and encountering cancer.

Most of the respondents picked more than one option (59:2). The students were able to remember that there is no singular cause of cancer, especially if it relies on environmental pathogenesis to occur. This finding concurs with those by several authors $[14,15,16,17$, $18,19,20,21,22,23,24,25]$.

\section{Attitude}

There was no significant association between 'Cancer is limited to certain people groups' (attitude) and 'Cancer is a punishment from God' (attitude) as it yielded $\chi^{2}=3.479$, df $=4$ and $p$-value $=0.481$. There is also no significant association with prevention and control, as represented by 'Monthly selfexamination for Cancer' (practices) that yielded $\chi^{2}=12.350$, df $=10$, and $p$-value $=0.262$. There is an association between attitude and knowledge (encountered cancer before) and another between attitude and practice (smoke cigarettes) since the $\mathrm{p}$-value for both is less than 0.05 . These results have been further illustrated in Table 7 in the Appendix.

Table 7. Cancer is Limited to Certain People Groups Versus Encountered Cancer before, Cancer is a Punishment from God, Smoke Cigarettes and Monthly self-examination for Cancer

\begin{tabular}{|l|l|l|l|}
\hline Cancer is Limited to Certain People Groups & $\chi^{2}$ & df & $\boldsymbol{p}$-value \\
\hline Encountered Cancer before (Attitude versus Knowledge) & 32.416 & 4 & 0.000 \\
\hline Cancer is a punishment from God (Attitude versus Attitude) & 3.479 & 4 & 0.481 \\
\hline Smoke cigarettes (Attitude versus Practice) & 42.270 & 6 & 0.000 \\
\hline Monthly self-examination (Attitude versus Prevention and Control) & 12.350 & 10 & 0.262 \\
\hline
\end{tabular}

Approximately $85.48 \%$ of the respondents said that cancer was not limited to certain people groups of people. The logic behind this reasoning was that everyone was at risk of developing cancer. However, this is not the case, as cancer needs multiple risk factors. Good examples include living downstream from processing and manufacturing companies and being exposed repeatedly to wastes like sulphates, sulphides, and even nitrous oxides, which exist in gaseous form. Other pollutants that could leak into water and soil are raw fecal matter, phosphates and nitrates, nitrites, sulphites, mercury, cadmium, and lead. Direct exposure to these (like in the case of a factory worker in a smelting company, hasten the process of cancer development, especially if the said worker is not properly protected at work, or does not get enough cash compensation for their hard work they put in $[4,5,6,7,8,9,10$, 11]. In a study, breast cancer was noted in females form wealthy ethnic groups, whereas the poor Africans suffered other cancers such as those of nasopharynx, all based on life experiences [17].

Most of the respondents believed that cancer was not a punishment from God, but a small ratio did. Christians (5:47), Hindus (0:2), Muslims (1:4) and Sikhs (0:2). This could be attributed to a number of reasons. One, a lot of 
politicians who succumb to this disease had some strange dealings or hurt people in their past. They are also well off, and their diet is a risk factor for cancer, especially if it does not allow for healthy habits like vegetable and fruit consumption. A diet that is richer in animal protein than everyone else. This has been proven to be detrimental to a lot of people. A diet that has more animal than plant-based protein, and less fibre intake than the average Kenyan, increases the number of radicalized ions in the body. It also leads to buildup of wastes, and these conditions might make the body weaker. This allows for rapid mutation of cancer cells. Another possibility might be the 'Hygiene Hypothesis' which states that people exposed to communicable and infectious diseases regularly like the common cold, chicken pox, typhoid, helminths infection and malaria might have stronger immune systems than people who do not have them. Most of these diseases are assumed to affect the lower socio-economic classes, as the richer people usually keep their houses in very clean conditions. In some study, postulated that people in lower socio-economic status believed that everything could cause cancer [26]. The same sentiment was shared by $[27,28]$. Several authors [19, 21, 29], on the other hand, postulated that people in the intermediate group believed in environmental causes of cancer, while those in the higher group believed in behavior and psychosocial causes of cancer. Second, Kenya is a predominantly religious country and attaches a lot of importance and pride to these characteristics. Drawing examples from Biblical Heroes like Job, it is easy for a lot of people to assume that cancer is a disease for those who have disobeyed God. In a study, beliefs which are assumptions and convictions held to be true based on past experiences, could be a factor here [30].

\section{Practices}

There was no significant association between 'Smoke cigarettes' (practices) and 'Monthly self-examination for Cancer' (prevention and control) as it yielded $\chi^{2}=11.760, \mathrm{df}=15, p$ value $=0.697$. There are associations with 'Encountered cancer before' (knowledge), 'Cancer is limited to certain people groups' (attitude), and 'Duration of keeping the windows open at home' (practices). This means that it is possible for practices to affect knowledge, attitudes, and other practices. These results have all been illustrated in Table 8 in the Appendix.

Table 8. Smoke Cigarettes versus Encountered Cancer before, Cancer is Limited to Certain People Groups, Duration of Opening Windows at Home and Monthly self-examination for Cancer

\begin{tabular}{|l|l|l|l|}
\hline Smoke Cigarettes & $\chi^{2}$ & Df & $\boldsymbol{p}$-value \\
\hline Encountered Cancer before (Practices versus Knowledge) & 25.304 & 6 & 0.0003 \\
\hline Cancer limited to certain people groups (Practices versus Attitudes) & 42.270 & 6 & 0.000 \\
\hline Duration of opening windows at home (Practices versus Practices) & 20.219 & 9 & 0.017 \\
\hline Monthly self-exam (Practices versus Prevention and Control) & 11.760 & 15 & 0.697 \\
\hline
\end{tabular}

Table 9. Monthly self-examination versus Encountered Cancer before, Cancer is Limited to People Groups, Smoked Cigarettes and Screened for Cancer before

\begin{tabular}{|l|l|l|l|}
\hline Monthly Self-Examination & $\chi^{2}$ & Df & $\boldsymbol{p}$-value \\
\hline Encountered Cancer before (Prevention and control versus Knowledge) & 7.831 & 10 & 0.645 \\
\hline Cancer limited to certain people groups (Prevention and control versus Attitude) & 12.350 & 10 & 0.262 \\
\hline Smoked cigarettes (Prevention and control versus Practice) & 11.760 & 15 & 0.697 \\
\hline $\begin{array}{l}\text { Screened for cancer before (Prevention and control versus Prevention and } \\
\text { Control) }\end{array}$ & 7.276 & 5 & 0.201 \\
\hline
\end{tabular}


Table 10. Association between Prevention and Knowledge, Attitude and Practice

\begin{tabular}{|l|l|l|l|}
\hline Prevention & Odds Ratio & p-value & 95\% CI \\
\hline Knowledge score & 1.154271 & 0.577 & $0.697,1.912$ \\
\hline Attitude score & 0.703692 & 0.255 & $0.384,1.289$ \\
\hline Practice score & 1.536422 & 0.042 & $1.015,2.326$ \\
\hline
\end{tabular}

Table 11. Correlation in Scores

\begin{tabular}{|l|l|l|l|l|}
\hline & Prevention score & Knowledge score & Attitude score & Practice score \\
\hline Prevention score & 1 & & & \\
\hline p-value & & & & \\
\hline Knowledge score & 0.0769 & 1 & & \\
\hline p-value & 0.5526 & & & \\
\hline Attitude score & -0.172 & 0.0387 & 1 & \\
\hline p-value & 0.1814 & 0.7649 & & \\
\hline Practice score & 0.2502 & -0.0104 & 0.1833 & 1 \\
\hline p-value & 0.0498 & 0.9361 & 0.1538 & \\
\hline
\end{tabular}

The majority $(88.71 \%)$ of the respondents did not smoke cigarettes and had never taken part in it, which is quite a good health habit. For the respondents who used tobacco in other forms, 2 out of 3 said they use it daily, which is a bad health habit. It is a well-known fact to a lot of Kenyans that cigarettes and other tobacco compounds have been responsible for a lot of cancer cases. Thankfully, WHO has been implementing measures that have cut down on advertisement, colorful packaging of cigarettes, and additional taxes for tobacco and tobacco products. Several authors $[16,23]$ have documented the ill-health caused by the use of tobacco. Tobacco use and even smoke from firewood use have been associated with high chances of cancer of the lungs [31].

Fifty-two out of sixty-two (85.25\%) respondents said they did not open their windows daily. This could be due to the type of window or the classes they have throughout the day. Only 4 respondents reported their houses did not have windows. This is usually the result of being attacked in a house that had windows or that it is all happening because of an omission made in the planning process. The final reason is that the windows could be deadlight and only allow light but cannot be opened. The lack of windows, and the option of not opening windows, however, increases the amount of radon gas present in houses. The type of floor is also responsible for this, as it has been reported houses that have lead paint, overgrowth of fungus or porous floors have a higher risk of Radon and Carbon (IV) oxide, Carbon (II) Oxide poisoning [32, 33].

\section{Prevention}

There was no significant association between 'Monthly self-examination for Cancer' (prevention and control) and 'Encountered Cancer before' (knowledge) as it yielded $\chi^{2}=$ $7.831, \mathrm{df}=10, p$-value $=0.645$. There was no significant association with 'Cancer is limited to certain people groups' (attitude) as it yielded $\chi^{2}=12.350, \mathrm{df}=10, p$-value $=0.262$. There was no significant association with 'Smoke cigarettes' (practices) as it yielded $\chi^{2}=11.760$, df $=15$, and $p$-value $=0.697$. There is no significant value with 'Screened for Cancer before' (prevention and control) as this variable yielded $\chi^{2}=7.276$, $\mathrm{df}=5$, and $p$-value $=0.201$. These results have been illustrated in Table 9 in the Appendix.

Sixty out of sixty-two (97\%) respondents had not been screened for any cancer. This is 
probably because, while they know they should go get the test done, they might actually feel burdened if they test positive. It would be like a death sentence to the recipient of the test results. Regular testing is important for that reason too. This finding of avoiding screening activities contravenes WHO (2020) health guidelines as it beats the purpose of making early diagnosis which is essential for better health outcomes. Some Study has also documented those fewer comprehensive surveillances on the ground are responsible for the late-diagnosed cases [34]. This could very well be termed dismal; every effort should be put in place to increase surveillance measures.
Only 17 female students against 26 male students self-examine at least once every month. The Medical students had the highest number of respondents who had never selfexamined themselves. There could be reasons for this, for example, busy schedules, or assignments, or shame and self-consciousness, as self-examination like for breast cancer make a lot of women shy. Self-examination is quite essential as it helps in making an early diagnosis of cancer which may enable appropriate action to be taken early enough for a better outcome [23].

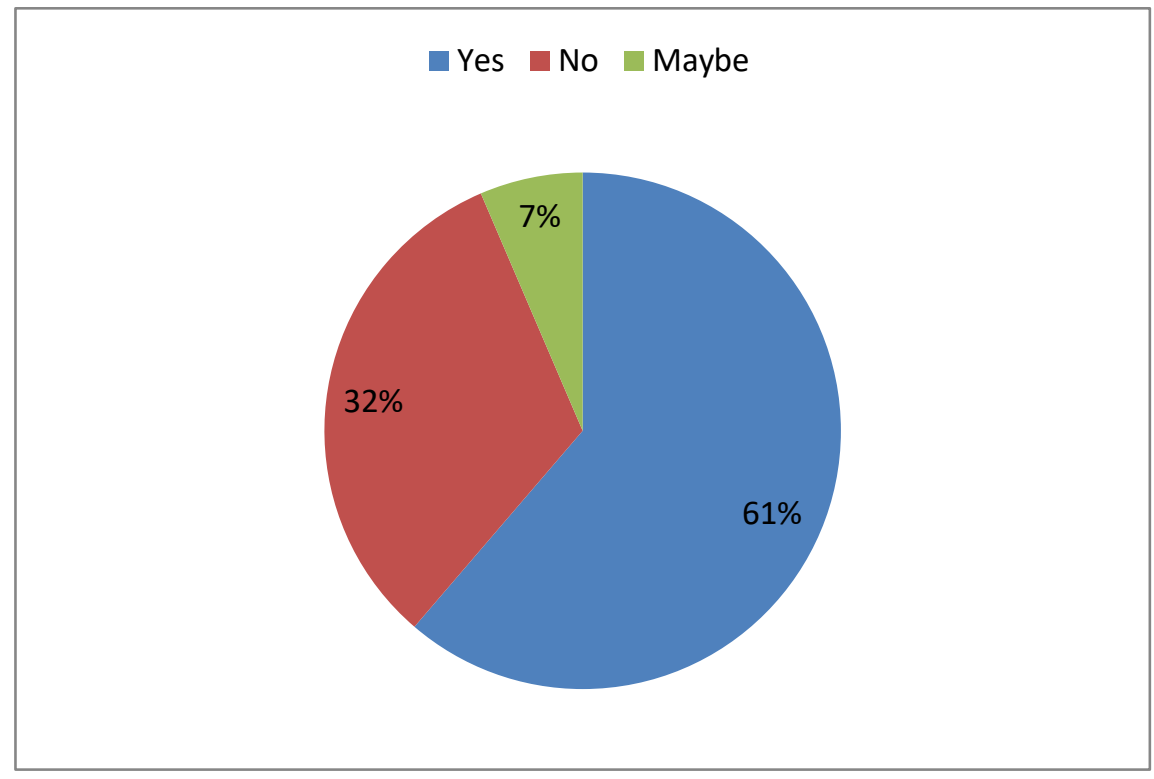

Figure 1. Encountered Cancer before Attending MOI University

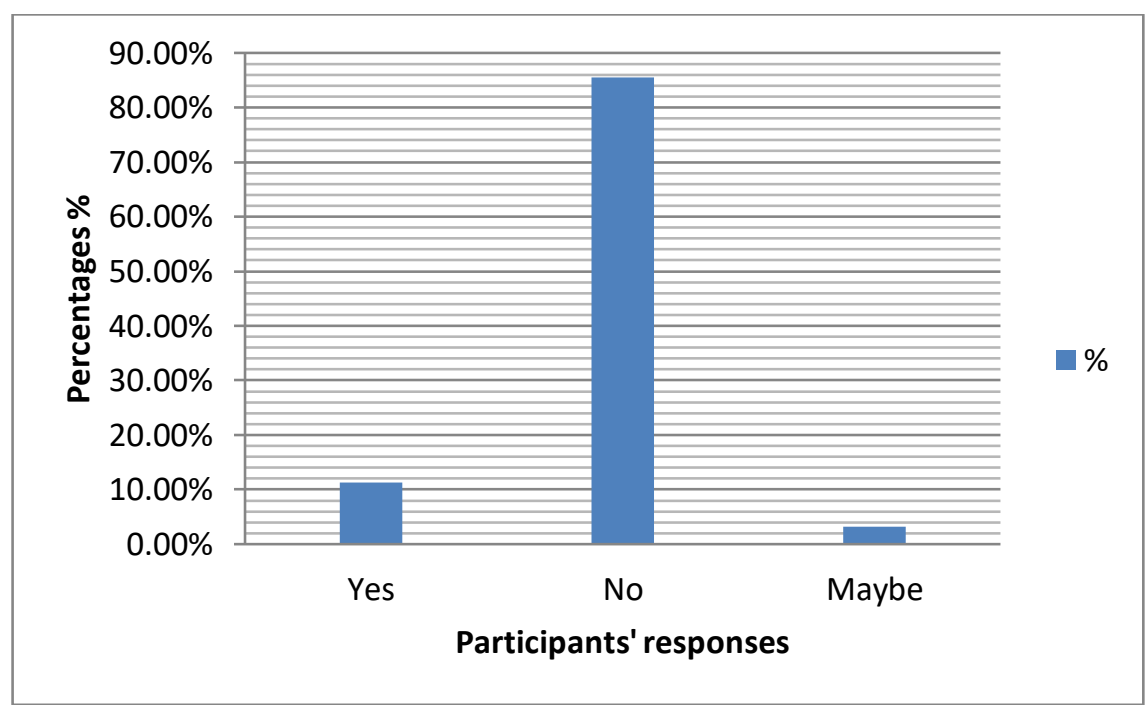

Figure 2. Cancer is Limited to Certain People Groups 


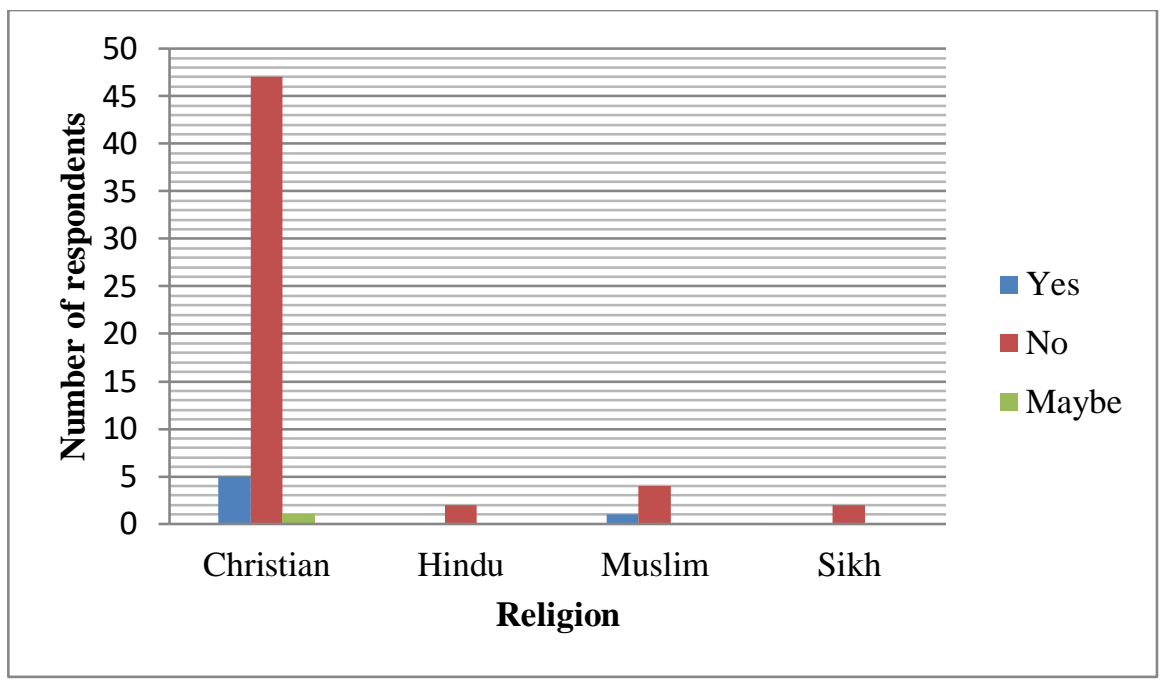

Figure 3. Cancer is a Punishment from God Plotted against the Religions of the Respondents

\section{Conclusion}

The study set out to evaluate whether the knowledge, attitude, and practices of the Moi University College of Health Sciences finalist undergraduate students on environmental carcinogens in Eldoret, Kenya was a viable study topic. In this study, the researcher concluded that:

The majority of finalist adult students were knowledgeable of carcinogens through various sources, with most of these sources being combinations of two or more sources of information. They, however, did not know much about the people groups at risk of exposure to carcinogens in the environment. This makes them vulnerable to the exposure to environmental carcinogens, even without their knowledge.

Although a good number of finalist adult students had a positive attitude, the majority had negative attitudes evidenced by being unaware of risks and the predisposed group, as well as not seeing the need for going for free testing. This puts them at a higher risk of unknown exposure to environmental carcinogens, or even worse, unmonitored cancer development. This was very risky for them, considering how many times they could get exposed to the carcinogens at work or brings them home to their families with them on their person.
The researcher noted that few finalist adult students observed good practices on environmental carcinogens and was disheartened to see quite a large number had poor practices that promoted environmental carcinogenesis. This would lead to an increase in the disease burden for the country and their families. This is especially heartbreaking as the youth are the future of the world.

A good number of finalist adult students observed the preventive measures fairly well, with a significant number carrying out selfexamination when they could, eating healthy, and working out when they could. This has been proven to boost the body's immune system in fighting cancer development, as these cells are at risk of developing at any time. The students attempted to live a healthy lifestyle and that was a step in the right direction.

\section{Acknowledgement}

The researcher is grateful to the following for being instrumental to her study, thesis writing and paper writing: Dr. Taratisio Ndwiga who was her supervisor, Dr. Josphat Otwelo who gave the idea of the study in 2016, Dr. Roselyne Lwenya for her advice, Dr. Barry Ramadhan Ayumba for his mentorship, all the Moi University College of Health Sciences students who aided and or took part in the study, the statisticians Dr. Gerald Lwande and 
Mr. Henry Mwangi for their assistance in data analysis and the School of Public Health in Texila American University for coordinating the Masters in Public Health program. She also acknowledges the Texila American Journal for the opportunity to publish the paper on her thesis.

\section{Conflict of Interest}

The first researcher is a Master of Public Health student at Texila American University, and the paper is based on her thesis with the

\section{References}

[1] Bell, DW. NIH, National Human Genome Research Institute. (2021). Carcinogen (Sourced from https://www.genome.gov/geneticsglossary/Carcinogen on 16th January 2021).

[2] NIH, National Cancer Institute. (2021). Carcinogen (Sourced from https://www.cancer.gov/publications/dictionaries/ca ncer-terms/def/carcinogen on 16th January 2021).

[3] Rogers, K. (2021). Carcinogen | Pathology (Sourced from https://www.britannica.com/science/carcinogen on 16th January 2021).

[4] Onyango, L. (2019). Kenya Regulator Shuts Down 4 Firms for Polluting Nairobi River. The East African (Sourced from www.theeastafrican.co.ke on $16^{\text {th }}$ May, 2020).

[5] Nyamai, F. (2017). Pollution Poses Grave Risk to Kenyans' Lives, Warn Experts. The Daily Nation (Sourced from https://nation.africa/kenya/news/pollution-poses grave risk to kenyans lives warn experts 486272 on $16^{\text {th }}$ May,2020)

[6] Gisesa N. (2013). Manyattas of Death: Up to 500 dead... and counting as mystery cancer devastates Marsabit, Kenya. Standard Media (Sourced from www.standardmedia.co.ke on $16^{\text {th }}$ May 2020).

[7] Wachira M. (2009). Areas that could be rich in oil, turns out to be valley of death. The Daily Nation (Sourced from https://www.whispersnorth.com/2019/08/04/area- same name. The second researcher is an alumnus of the Texila American University (postgraduate) and was appointed the local guide/supervisor of the student. The third researcher is an academician and reviewer of the study. The study was self-sponsored and had no external funding. As thus, the declaration is that there is no conflict of interest.

that-could-be-rich-in-oil-turns-out-to-be-valley-ofdeath/ on $16^{\text {th }}$ May, 2020).

[8] Environmental Health Criteria; 231 (EHC_231). 2005. Environmental Health Criteria for Bentonite, Kaolin, And Selected Clay Minerals (Sourced from http://www.inchem.org/documents/ehc/ehc/ehc231.h tm on June 2020).

[9] World Health Organization (WHO). (2011). Guidelines for Drinking-water Quality. (Sourced from

http://apps.who.int/iris/bitstream/handle/10665/4458 4/9789241548151_eng.pdf;jsessionid=96692EF25C 4658F110A468D556B8C931? sequence $=1$ on April, $2^{\text {nd }} 2020$ ).

[10] International Agency for Research on Cancer (IARC). (2010). IARC Monographs on the Evaluation of Carcinogenic Risks to Humans: Ingested Nitrate and Nitrite, and Cyanobacterial Peptide Toxins (Sourced from https://monographs.iarc.who.int/wpcontent/uploads/2018/06/mono94.pdf on 2nd April, 2020).

[11] Jarrard DF. (2005). Does zinc supplementation increase the risk of prostate cancer? Arch Ophthalmol. 2005 Jan;123(1):102-3. doi: 10.1001/archopht.123.1.102. PMID: 15642820.

[12] Moi Teaching and Referral Hospital (MTRH). (2020). About Us (Sourced from www.mtrh.go.ke on 27 $7^{\text {th }}$ March, 2020).

[13] Mugenda, OM., \&Mugenda, AG. (2003). Research methods, quantitative and qualitative approaches. Nairobi. ACTS Press. 
[14] American Cancer Society (ACS). 2019. Breast cancer risk factors you cannot change: Genetic risk factors (Sourced from www.cancer.org/cancer/breastcancer/risk-andprevention/breast-cancer-risk-factors-you-cannotchange.html on 28 ${ }^{\text {th }}$ March 2020).

[15] Apostolou P, Fostira F. (2013). Hereditary breast cancer: the era of new susceptibility genes. Biomed Res Int. 2013:1-11. Available at: Biomed Res Int.2013; 2013: 747318.doi.10.1155/2013/747318.Epub 2013 Mar 21.

[16]Doll, R. \&. Peto, R. (1981). The causes of cancer: Quantitative estimates of avoidable risks of cancer in United States today. New York: Oxford University Press.

[17] Korir A., Wang E.Y., Sasieni P., Okerosi N., Ronoh V., Parkin D.M. (2016). Cancer Risks in Nairobi (2000-2014) By Ethnic Group. International Journal of Cancer (Sourced from https://doi.org/10.1002/ijc.30502 on 5th July 2020 on $5^{\text {th }}$ July 2020).

[18] Maiyoh G.K., Tuei V.C. (2019). Rising Cancer Incidence and Role of The Evolving Diet in Kenya (Sourced from https://doi.org/10.1080/01635581.2018.152010 on 5th July, 2020).

[19] Molina Y, Zimmermann K, Carnahan L.R, Paulsey E, Bigman C.A, Khare M.M, Zahnd W, Jenkins W. (2018). Rural Women's Perceptions About Cancer Disparities and Contributing Factors: A Call to Communication. $J$ Cancer Educ. 33(4):749-756. doi: 10.1007/s13187-017-1196-5 (Sourced from www.nih.ncbi.nlm.govon $30^{\text {th }}$ March, 2020).

[20] Mizoue T, Inoue M, Wakai K, Nagata C, Shimazu T, Tsuji I, Tsugane S. (2008). Research Group for Development and Evaluation of Cancer Prevention Strategies in Japan. Alcohol drinking and colorectal cancer in Japanese: a pooled analysis of results from five cohort studies. American Journal of Epidemiology. 167:1397-1406. (Sourced from www.nih.ncbi.nlm.gov on $12^{\text {th }}$ April, 2020).

[21]Parsa N. (2020). Environmental Factors Inducing Human Cancers. Iranian Journal of Public
Health. (Sourced from www.ncbi.nlm.nih.gov on $31^{\text {st }}$ March, 2020).

[22] Rushton L. (2003). How Much Does the Environment Contribute to Cancer? (Sourced from https://dx.doi.org/10.1136/oem.60.2.150, https://oem.bmj.com/content/60/2/150.full on $1^{\text {st }}$ April 2020).

[23] Samrein BM Ahmed, Sara Amer, Amal Hussein, Drishti D Kampani, Nour Al Hasham, Mohamed M Assker, NourShawa, Dima Saleh \& Khalid O Alfarouk (2020). Assessing the knowledge of environmental risk factors for cancer among the United Arab Emirate population: A pilot study. International Journal of Environmental Research and Public Health, 17, 2984; doi: 10.3390/ijerph17092984.Also as: ijerph-17-02984v2.

[24] Wendt, C. \&Margolin, S. (2019). Identifying breast cancer susceptibility genes-a review of the genetic background in familial breast cancer.ActaOndal (Madr). 58(2):135-46.

[25] Whiteman, H. (2015). Medical News Today: Most cancer cases 'caused by lifestyle, environmentnot bad luck. (Sourced from www.medicalnewstoday.com on $28^{\text {th }}$ March, 2020). [26] Peretti-Watel P, Fressard L, Bocquier A, Verger P. (2016). Perceptions of cancer risk factors and socioeconomic status. A French study. Doi: 10.1016/j.pmedr.2016.01.008 (sourced from www.nih.ncbi.nlm.gov on $2^{\text {nd }}$ April, 2020).

[27] Davison C., Frankel S., Davey S.G. (1992). The limits of lifestyle; reassessing 'fatalism' in the popular culture of illness prevention.Soc. Sci. Med. 34(6):675-685 (Sourced from www.googlescholar.com on $3^{\text {rd }}$ April 2020).

[28]Douglas M. (1992). Risk and Blame.Routledge; London (Sourced from www.googlescholar.com on $3^{\text {rd }}$ April, 2020).

[29] Herzlich C. (1973). Health and Illness.London: Academic Press. (Sourced from www.googlescholar.com on $2^{\text {nd }}$ April, 2020).

[30] Kumar M. 2018. Owlcation: The Relationship Between Beliefs, Values, Attitudes and Behaviours (Sourced from https://owlcation.com/socialsciences/Teaching-and-Assessing-

Attitudes\#: :text=Attitudes\%20arise\%20out\%20of 
$\% 20$ core,beliefs $\% 20$ and $\% 20$ values) $\% 20$ are $\% 20$ expr essed on $5^{\text {th }}$ July, 2020).

[31]Boffetta P, Nyberg F. Contribution of environmental factors to cancer risk. Br Med Bull. 2003; 68:71-94. doi: 10.1093/bmp/ldg023. PMID: 14757710.

[32] World Health Organization (WHO). (2020). Cancer. (Sourced from www.who.int/cancer/screening on April, 2nd 2020).
[33] World Health Organization (WHO). (2016).

Radon and Health (Sourced from www.who.int/radonandhealth on April, 1st 2020). [34] Kaleli S., Deveci A., Eskiler G.G. (2018). Which Environment Makes Cancer? Oncol Res Rev1: doi:10.15761/ORR.1000115 (Sourced from www.oatext.com/which-environment-makes-cancer/ on $6^{\text {th }}$ July 2020). 